\title{
EKSTRAKSI LANTANUM DENGAN SENYAWA PENGEMBAN TRIBUTYL PHOSPHATE (TBP) DAN DI(2 ETYL HEXYL) PHOSPORIC ACID (D2EHPA) DALAM KEROSEN
}

\author{
M. Cholid Djunaidi*, Buchari** \\ * Jurusan Kimia Universitas Diponegoro \\ **Jurusan Kimia Institut Teknologi Bandung
}

\section{ABSTRACT}

Telah dilakukan penelitian ekstraksi La (III), dengan fasa organik senyawa pengemban tributyl phosphate (TBP) dan di(2-etylhexyl) phosporic acid (D2EHPA) yang dilarutkan dalam kerosene. Ekstraksi dilakukan dengan variasi $\mathrm{pH}$, konsentrasi senyawa pengemban, dan kekuatan ion (nitrat). Pemantauan konsentrasi logam lantanum di fasa air dilakukan secara spektrofotometri UV-Vis dengan menggunakan natrium alizarin sulfonat (NAS) sebagai senyawa pembentuk warna dan diukur pada panjang gelombang $528 \mathrm{~nm}$. Senyawa pengemban D2EHPA dalam transpor logam lantanum memperlihatkan keterlibatan ion hidrogen, tetapi tidak untuk nitrat. Hal ini berlawanan dengan TBP. Campuran TBP dan D2EHPA dengan perbandingan 0,2 M:0,8 memperlihatkan sifat yang mengikuti komponen utamanya (D2EHPA). Senyawa pengemban campuran TBP-D2EHPA memberikan efek sinergi dengan bertambahnya fraksi mol D2EHPA.Proses stripping (pemisahan/recovery) dipelajari dengan membandingkan $\mathrm{pH}$ fasa penerima 1 dan 3 sedangkan $\mathrm{pH}$ larutan air (fasa umpan) adalah 3. Pada $\mathrm{pH}$ fasa penerima 1 recovery La yang diperoleh jauh lebih baik daripada $\mathrm{pH} 3$.

\section{EXTRACTION OF LANTANUM BY DI-2 ETHYL HEXIL PHOSPORIC ACID (D2EHPA) AND TRIBUTYL PHOSPHATE (TBP) AS CARRIER IN KEROSENE, AND CARACTERIZATION COMPLEX HAVE BEEN FORMED}

\begin{abstract}
.
Extraction of lantanum has been studied. As a organic phase is TBP (tributylphosphate) and D2EHPA (di-2-ethylhexyl phosphoric acid) in kerosene solvent. Determination of lanthanum concentration was, carried out by spectrophotometry with NAS (sodium alizarin sulfonat) as colouring reagent. Absorbance of the solution was determined at $528 \mathrm{~nm}$.. Extraction was done by variation of $\mathrm{pH}$ carrier compound and ionic strenght nitrate. Carrier D2EHPA in lanthanum transport showed that hidrogen ion are involved, while nitrate compound was not. That is contradicted with TBP. Mixture of them (with ratio 0,2 M TBP : 0,8 M D2EHPA) showed caracteristic that followed the main component (D2EHPA).Stripping proses have been studied by compare $\mathrm{pH}$ stripping phase 1 and $3, \mathrm{pH}$ feed phase is 3.Recovery of $\mathrm{La}$ at $\mathrm{pH}$ stripping phase 1 is better than $\mathrm{pH} 3$.
\end{abstract}

\section{PENDAHULUAN}

Kelompok unsur lanthanida sangat sulit untuk dipisahkan dengan metode tradisional karena sifat kimia yang mirip. Unsur ini dalam keadaan murni sangat diperlukan pada industri elektronik. Salah satu metode pemisahan yang masih dapat dikembangkan adalah ekstraksi pelarut.
Ekstraksi pelarut merupakan salah satu teknik pemisahan suatu komponen dari komponen lain dalam campurannya. Karena ion-ion logam umumnya tidak larut dalam pelarut organik, maka harus dikomplekskan dulu dengan suatu pereaksi membentuk kompleks yang tidak bermu- 
atan sehingga kompleks tersebut dapat larut dalam pelarut organik. ${ }^{(2)}$

Untuk memisahkan LTJ secara ekstraksi pelarut umumnya digunakan reagen-reagen yang mempunyai sifat yang berbeda, yaitu ekstraktan pensolvasi seperti tri-nbutil fosfat (selanjutnya disebut TBP) yang digunakan untuk memperoleh LTJ dari media nitrat, ekstraktan penukar kation termasuk asam organofosforat, fosfonat dan asam fosfonat atau asam karboksilat bisa digunakan untuk media asam hidroklorida, nitrat atau sulfat, dan ekstraktan penukar anion seperti garam ammonium kuartener. Dari sejumlah besar reagen pengekstrak ini, organofosforat adalah salah satu yang banyak dipelajari untuk ekstraksi LTJ , khususnya asam di2-etilheksil fosforat (D2EHPA) ${ }^{(1,3)}$. Kadang-kadang, campuran dua ekstraktan akan menaikkan pemisahan unsur individual (efek sinergi) ${ }^{(1)}$.

Penggunaan ekstraktan campuran yang diharapkan menambah ekstraksi (mempunyai efek sinergis) sampai saat ini masih banyak dikaji. Healy melaporkan ekstraksi sinergi (ekstraksi pelarut) uranium(VI), thorium, lanthanida(III), actinida(III) dan alkali tanah dengan HTTA-TBP, HTTATBPO dan HTTA-TPP; (TPP adalah tripenyl phospate $)^{(4)}$. Sedangkan ekstraksi logam tanah jarang dengan metode membran cair berpendukung (SLM) telah diteliti efek sinergis dari campuran ekstraktan seperti TBP-TOPO, TBP-D2EHPA, TOPOD2EHPA dengan hasil yang memberikan efek sinergi terbesar adalah campuran TBP-D2EHPA ${ }^{(5)}$.

\section{EKSPERIMEN}

Larutan stok 1000 ppm La (III) dalam 1 $\mathrm{ml} \mathrm{HNO}_{3}$ pekat dibuat dengan melarutkan $\mathrm{La}_{2} \mathrm{O}_{3}$ murni (Merck) dengan max. $0,0005 \% \mathrm{Ca}$.

Bahan-bahan yang digunakan berderajat pro analysis (pa.), Di(2etthylhexyl) phosporic acid (SIGMA) dengan kemurnian 95\% dan TBP dibuat oleh Aldrich. Larutan stok D2EHPA dibuat dalam kerosene, yang didestilasi dari minyak tanah dengan fraksi $200-220^{\circ} \mathrm{C}$ (sebelumnya minyak tanah diekstrak untuk meniadakan senyawa aromatiknya dengan $\mathrm{H}_{2} \mathrm{SO}_{4}$ ).

Larutan umpan dengan konsentrasi awal $100 \mathrm{ppm}$ dibuat dari larutan induk, dan keasaman diatur dengan $\mathrm{HNO}_{3}$ dan $\mathrm{NaOH}$ encer. Kekuatan ion dipertahankan konstan pada $0,1 \mathrm{~mol} / 1\left(\mathrm{HNO}_{3}, \mathrm{NaNO}_{3}\right)$. $\mathrm{pH}$ larutan diatur dengan $\mathrm{pH}$ meter Orion model 420 A. Pengukuran La dilakukan dengan menggunakan spektrofotometer UV-VIS Beckman DU 7500.

Studi transport dilakukan pada konsentrasi lanthanum $100 \mathrm{ppm}$, lama pengadukan 15 menit, perbandingan fasa umpan-fasa organik $10 \mathrm{ml}: 10 \mathrm{ml}$, perbandingan fasa organik-fasa penerima $5 \mathrm{ml}: 5 \mathrm{ml}$. Variabel yang diubah meliputi $\mathrm{pH}$ fasa air dan penerima, komposisi, jenis dan konsentrasi senyawa pengemban di fasa organik, konsentrasi ion nitrat di fasa air.

Ekstraksi pelarut menggunakan beaker glass yang diputar dengan stirer pada kecepatan konstan. Stirer yang digunakan Fisher Scientific Thermix Stirrer 120 MR 


\section{HASIL DAN PEMBAHASAN}

1. Pengaruh Ion Hidrogen, ion nitrat fasa umpan, dan senyawa pengemban.

Pada ekstraksi La(III) dengan D2EHPA terlihat bahwa \% ekstraksi meningkat dengan naiknya konsentrasi D2EHPA (gb 1)

Pada konsentrasi D2EHPA yang relatif kecil mampu terjadi transport yang cukup berarti. Jadi carier penukar kation (D2EHPA) cukup efektif untuk transport La.

Keterlibatan ion hidrogen yang cukup signifikan pada fasa umpan terhadap ekstraksi $\mathrm{La}$ dapat dilihat pada gambar $2 \mathrm{a}$ dan $2 b$. Penurunan $\mathrm{pH}$ (kenaikan ion hidrogen) pada fasa umpan cukup signifikan. Konsentrasi D2EHPA yang makin besar dan meningkatkan konsentrasi kenaikan ion hidrogen pada fasa umpan transport La. Hal ini sesuai peran ekstraktan D2EHPA sebagai ekstraktan penukar kation $^{(6)}$, dimana ion hidrogen yang dimilikinya dipertukarkan dengan ion La. Semakin banyak ion hidrogen yang dipertukarkan semakin besar juga ion La yang tertransport.

Ion $\mathrm{NO}_{3}{ }^{-}$tidak meningkatkan transport (\% ekstraksi), tetapi cenderung menurunkan. Hal ini sesuai dengan persamaan reaksi 2., dimana ion Nitrat akan menyaingi $\mathrm{La}$ (III) berikatan dengan D2EHPA (Gb3) Reaksi ${ }^{(7)}$ :

$\mathrm{La}^{3+}(\mathrm{aq})+3[\mathrm{D} 2 \mathrm{EHPA}]_{2}(\mathrm{o})$

$\left.\Leftrightarrow \mathrm{La}(\mathrm{D} 2 \mathrm{EHPA})_{2}\right]_{3}(\mathrm{o})+3 \mathrm{H}^{+}$

$\mathrm{H}^{+}(\mathrm{aq})+\mathrm{NO}_{3}^{-}(\mathrm{aq})+2 \mathrm{H}_{2} \mathrm{O}+(\mathrm{D} 2 \mathrm{EHPA})_{2}(\mathrm{o})$

$\Leftrightarrow\left(\text { D2EHPA. } \mathrm{H}_{2} \mathrm{O}\right)_{2} \cdot \mathrm{HNO}_{3}(\mathrm{o})$
Ekstraksi La (III) dengan TBP pada pH 3 konsentrasi dengan $\mathrm{I}=0,1$ relatif kecil yaitu di bawah $10 \%$. Ini berarti bahwa kemampuan mengektraksi TBP terhadap logam lantanum yang relatif kecil.Hal ini karena sifat TBP yang mudah terhidrasi membentuk TBP. $\mathrm{H}_{2} \mathrm{O}^{(4)}$, air yang selalu menyertai ekstraksi nitrat ${ }^{(1)}$, banyaknya mekanisme solvasi lain yang terjadi selain solvasi kompleks $\operatorname{logam}^{(6,7,8)}$, polimerisasi yang mungkin terjadi pada konsentrasi tinggi $i^{(9)}$, dan kondisi percobaan yang digunakan bukan kondisi optimalnya (Gambar 4 a). Rydberg mengatakan transport TBP optimal pada $\mathrm{pH}$ tinggi, dengan asam nitrat yang rendah ${ }^{(1)}$

Keterlibatan ion hidrogen dalam transport La dengan pengemban TBP terlihat pada gambar $4 \mathrm{~b}$. Ion hidrogen dapat dikatakan tidak terlibat dalam ekstraksi dengan melihat kecilnya penurunan $\mathrm{pH}$ yang terjadi.Hal ini dipertegas dengan tidak ada hubungan yang jelas antata prosen ekstraksi dengan penurunan $\mathrm{pH}(\mathrm{Gb} .4 \mathrm{c})$.

Sedangkan ion nitrat berperan dalam ekstraksi $\mathrm{La}$ (III). Hal ini terlihat dengan naiknya \% ekstraksi $\mathrm{La}(\mathrm{IH})$ dengan nilai yang signifikan dengan adanya $\mathrm{NaNO}_{3}$ (Gb.5). Hal ini sesuai dengan persamaan 3 , dimana ion nitrat terlibat dalam reaksi pembentukan kompleks. Penambahan $\mathrm{NaNO}_{3}, 0,5 \mathrm{M}$ dan $1 \mathrm{M}, \%$ ekstraksinya lebih kecil dibandingkan dengan $0,1 \mathrm{M}$, ini karena terjadinya kompetisi antara La (III) dengan ion nitrat berlebih dalam berikatan dengan TBP(pers .4).

Reaksi ${ }^{(11)} \mathrm{La}^{3+}(\mathrm{aq})+3 \mathrm{NO}_{3}{ }^{-}(\mathrm{aq})+3 \mathrm{TBP}(\mathrm{o})$

$\Leftrightarrow \mathrm{La}\left(\mathrm{NO}_{3}\right)_{3}(\mathrm{TBP})_{3}(\mathrm{o})$ 
$\mathrm{H}^{+}(\mathrm{aq})+\mathrm{NO}_{3}{ }^{-}(\mathrm{aq})+\mathrm{nTBP}(\mathrm{o})$

$\Leftrightarrow \mathrm{HNO}_{3} \cdot \mathrm{nTBP}(\mathrm{o})$

Ekstraksi La (III) dengan pengemban campuran TBP-D2EHPA pada $\mathrm{pH} 2,3$ dan 5 memperlihatkan pola yang sama yaitu mulai terjadinya efek sinergis pada perbandingan TBP-D2EHPA $0,7 \mathrm{M}: 0,3$ M. (Tabel 1)

Tabel 1. \% ekstraksi La pada berbagai perbandingan konsentrasi TBP: D2EHPA pada $\mathrm{pH} 2,3$ dan 5

\begin{tabular}{|c|c|c|c|}
\hline \multirow{2}{*}{$\begin{array}{c}\text { Fraksi mol } \\
\text { D2EHPA }\end{array}$} & \multicolumn{3}{|c|}{$\%$ Ekstraksi } \\
\cline { 2 - 4 } & $\mathrm{pH} \mathrm{2}$ & $\mathrm{PH} \mathrm{3}$ & $\mathrm{pH} \mathrm{5}$ \\
\hline 0 & 0 & 0 & 23.9 \\
\hline 0,1 & 55,4 & 93,4 & 98,6 \\
\hline 0,2 & 87,84 & 95,9 & $\sim 100$ \\
\hline 0,3 & 93,7 & $\sim 100$ & $\sim 100$ \\
\hline 0,4 & 93,6 & 99,5 & $\sim 100$ \\
\hline 0,5 & 95,4 & 99,7 & $\sim 100$ \\
\hline 0,6 & 98 & $\sim 100$ & $\sim 100$ \\
\hline 0,7 & 97,9 & $\sim 100$ & $\sim 100$ \\
\hline 0,8 & 98,7 & $\sim 100$ & $\sim 100$ \\
\hline 0,9 & 94,7 & 97,4 & $\sim 100$ \\
\hline 1 & 92,4 & 96,6 & 99,8 \\
\hline
\end{tabular}

Pada campuran TBP-D2EHPA terjadi penurunan $\mathrm{pH}$ pada fasa air (umpan) yang cukup signifikan dengan bertambahnya konsentrasi D2EHPA dengan pola yang sama dengan transportnya.

Pengaruh garam $\mathrm{NaNO}_{3}$, menunjukkan bahwa \% ekstraksi makin besar dengan meningkatnya konsentrasi garam $\mathrm{NaNO}_{3}$ (Gb. 7) Hal ini terjadi karena fungsi garam 'salting out' lebih berperan pada pe- ngemban netral dengan mekanisme ekstraksi solvasi ${ }^{1,9}$.

2. Proses Pemisahan (stripping) dengan Ekstraksi Pelarut.

Pada proses pemisahan (stripping), dilakukan perbandingan antara proses pemisahan dengan $\mathrm{pH} 1$ dan $\mathrm{pH}$ 3. Pada kedua $\mathrm{pH}$ tersebut, dengan naiknya konsentrasi D2EHPA pada fasa organik terjadi penurunan \% recovery. Dengan bertambahnya konsentrasi D2EHPA kompleks yang terbentuk semakin kuat (ditandai dengan transport yang semakin naik) tapi dipihak lain semakin sulit pemisahannya. (Gb 8a) Pada fasa penerima (stripping) dengan $\mathrm{pH} 1, \%$ recovery cukup besar ( pada per bandingan TBP:D2EHPA $0.4 \mathrm{M}: 0,6 \mathrm{M}$ mencapai $100 \%$ ). Sedangkan pada $\mathrm{pH} 3$, $\%$ recovery yang diperoleh sangat kecil bahkan mendekati nol .Hal ini terjadi karena untuk memisahkan ion lantanum yang diikat oleh pengemban campuran dengan komponen dominan D2EHPA dibutuhkan ion hidrogen yang cukup melimpah yang terpenuhi pada $\mathrm{pH} 1$.

Hubungan perubahan $\mathrm{pH}$ pada fasa air penerima dengan proses ekstraksi (penurunan $\mathrm{pH}$ ) dan proses pemisahan (kenaikan $\mathrm{pH}$ ) pada pemisahan $\mathrm{pH} 1$ dan 3 dapat dilihat pada gb $8 b$ dan $9 b$. Pada pemisahan $\mathrm{pH} 1$, terlihat kenaikan $\mathrm{pH}$ fasa air penerima yang semakin meningkat dengan naiknya konsentrasi D2EHPA pada komposisi campurannya. Pada pemisahan $\mathrm{pH} 3$, terjadi penurunan $\mathrm{pH}$ di fasa penerima yang semakin meningkat dengan naiknya konsentrasi D2EHPA. 
Hal ini terjadi karena dalam proses kompleks-dekompleksasinya D2EHPA melibatkan ion hidrogen sedangkan TBP lebih mempunyai affinitas terhadap air dan asam (ditandai dengan keruhnya fasa air penerima, sehingga $\mathrm{pH}$ fasa air penerima turun).

\section{KESIMPULAN.}

1. Mekanisme transpor logam La (III) melalui ekstraksi pelarut dipengaruhi oleh gradien konsentrasi, yaitu ion hidrogen $(\mathrm{pH})$, kekuatan ion, serta senyawa pengemban.

2. Senyawa pengemban campuran TBPD2EHPA memberikan efek sinergis dengan bertambahnya transpor La(III)

3. Pada ekstraksi pelarut pengemban tunggal D2EHPA memperlihatkan keterlibatan ion Hidrogen dalam transpor La sedangkan ion nitrat tidak. Sebaliknya dengan pengemban tunggal TBP keterlibatan ion nitrat terlihat nyata, sedangkan ion hidrogen tidak. Untuk transpor dengan pengemban campuran TBP-D2EHPA keterlibatan ion hidrogen jelas kelihatan, tidak demikian dengan nitrat.

4. Kompleks campuran TBP-D2EHPA yang memberikan sinergi optimal (perbandingan $0,2 \mathrm{M}: 0,8 \mathrm{M}$ ) mempunyai sifat yang mengikuti komponen utamanya yaitu D2EHPA.

5. Recovery $\mathrm{La}$ (III) dengan pengemban D2EHPA membutuhkan konsentrasi ion Hidrogen yang cukup untuk hsil yang baik.

\section{DAFTAR PUSTAKA}

1. Rydberg., Principles and Practices of Solvent Extraction, Marcel D., New York, 1992, pp. $393-412$

2. Morrison, G.H., Freiser, H., Solvent Extraction in Analytical Chemistry, John Wiley \& Sons Inc. , New York, 1957

3. Moreno,C., Permeation of neodymium and praseodymium through supported liquid membranes containing di-(2ethylhexyl)phosphoric acid as a carrier. Journal of Membran Science, 1993,81, 121-126

4. De, A, Khopkar,S, Chalmer,RA,Solvent Extraction of Metals, Van Nostrand Reibhold Com, 1970, London

5. Aminuddin S, Buchari., Pemisahan Lantanum dan Cerium Dengan Teknik Membran Cair Berpendukung. Seminar Nasional Kimia'97, 1997, 9-13.

6. Kopunec, R, Manh, Th. Carrier-Mediated Transport of Rare Earth Elements Through Liquid Membranes.III. Transport of Sc, Y, Ce, Eu, Gd, Tm, Yb Through Supported Liquid Membrane Containing DEHPA. Journal of Radioanalytical and Nuclear Chemistry, 1992, 163,131- 144

7. Yuji, N. Stattus of Rare Earhs in the Word Evaluation of Their Resources. Proceeding International Conference on Rare Earth Minerals and Minerals for Electronics Uses;1996, 7-1

8. Shin Juang,Ruey., Analysis of transport rates of euopium (III) across an organophosphinic acid supported liquid 
membrane.Journal of Membran Science, 1996, $110,13-23$.

9. Khopkar,SM. Konsep Dsasar Kimia Analitik,Penerbit U1, Jakarta, 1990 , pp 54-106

10. Kapunec, R, Carrier-Mediated Transport of Rare Earth Elements Through Liquid Membranes, III. Transport of Sc, Y, Ce,
Eu, Gd, Tm, Yb Through Supported Liquid Membrane Containing TBP J.of Radioanalytical and Nuclear Chemistry, 1993, 1, 51-66।

11. Spedding, F.H., Daane, A.H., The Rare Earths, John Wiley \& Sons, Inc., New York, 1961, p.1-48,571-605. 


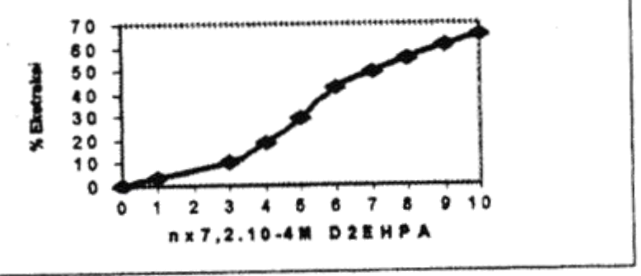

Gambar 1. Pengaruh konsentrasi senyawa pengemban D2EDPA terhadap \% ektraksi La.

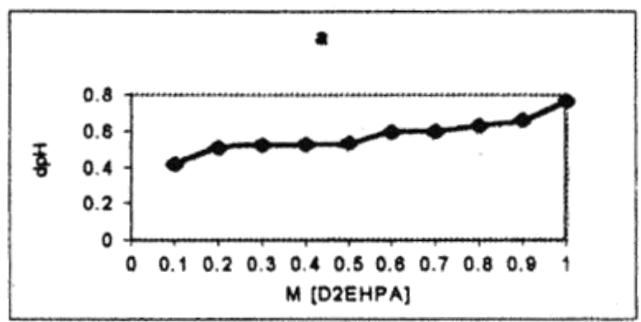

Gambar 2 (a). Kurva Pengaruh Konsentrasi D2EHPA dengan penurunan pH (dpH)

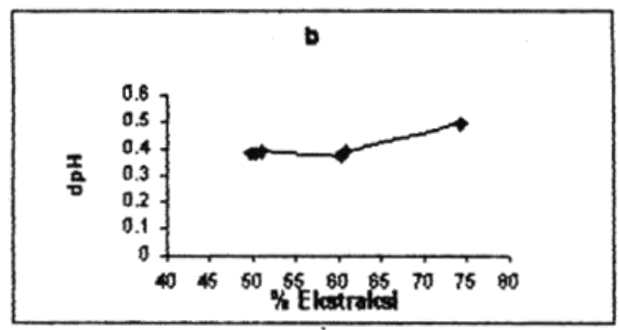

Gambar 2 (b). Kurva Hubungan \% Ekstraksi La Terhadap Penurunan pH (dpH)

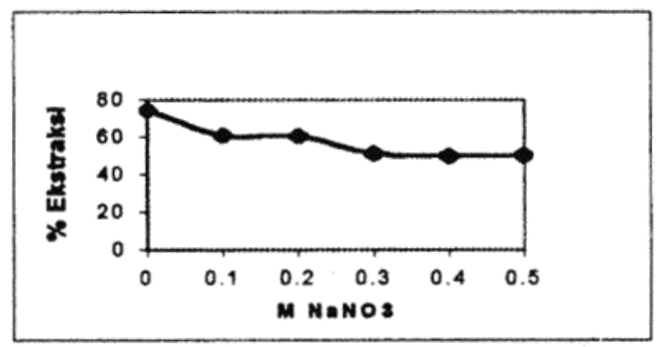

Gambar 3. Kurva Distribusi La dengan Carier D2EHPA pada berbagai konsentrasi $\mathrm{NaNO}_{3}$ 


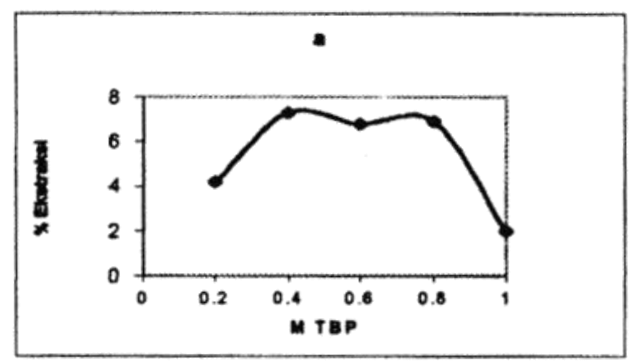

Gambar 4 (a) .Kurva Hubungan M [TBP] dengan \% Ekstraksi La

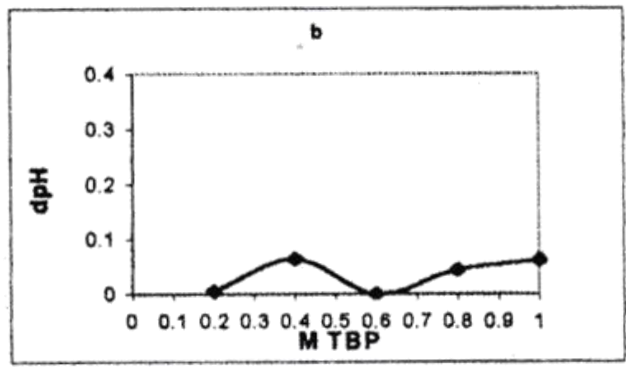

Gambar 4 (b). Kurva Hubungan M [TBP] dengan Penurunan pH

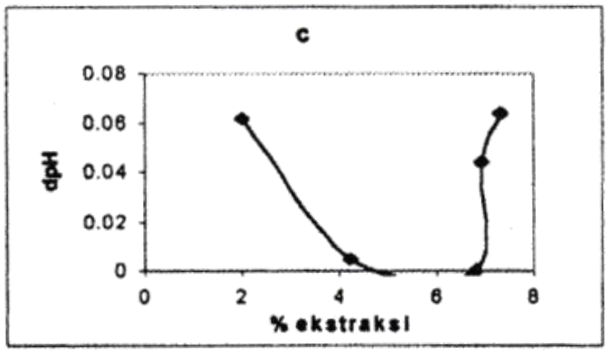

Gambar 4 (c) .Kurva Hubungan \% ekstraksi dengan Penurunan pH

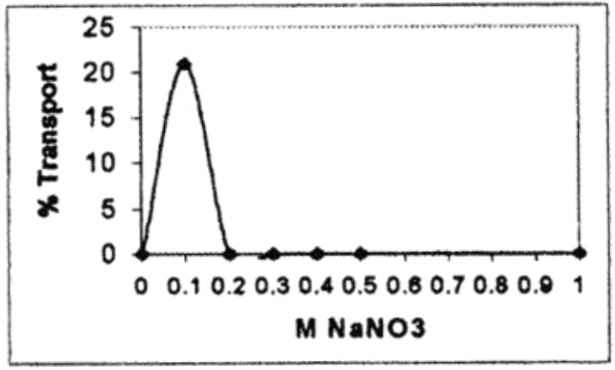

Gambar 5 Kurva Hubungan antara $\mathrm{MNaNO}_{3}$ dengan \% ekstraksi dengan carier TBP. 


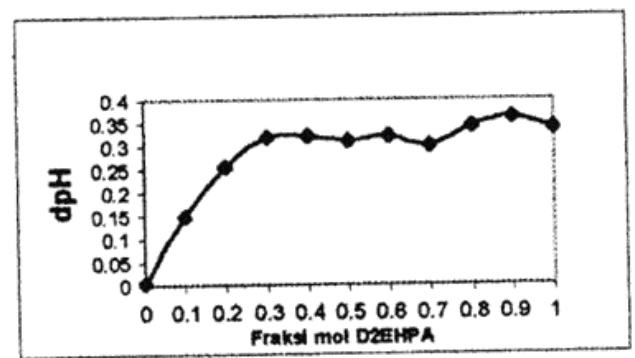

Gambar 6 Kurva Hubungan Fraksi mol D2EHPA pada campuran TBP-D2EHPA dengan penurunan $\mathrm{pH}(\mathrm{dpH})$ pada ekstraksi pelarut pada $\mathrm{pH} 3$.

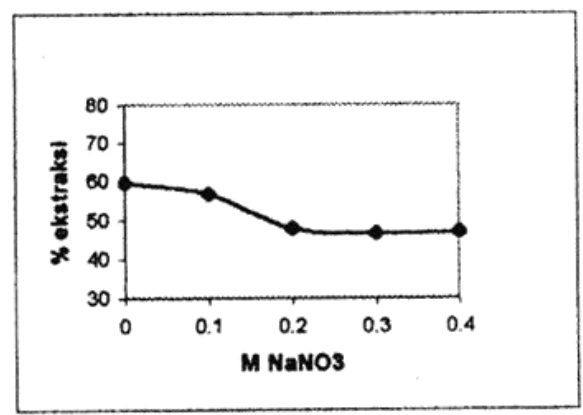

Gambar 7 Kurva Hubungan \% ekstraksi dengan $\left[\mathrm{NaNO}_{3}\right]$ dengan pengemban campuran.

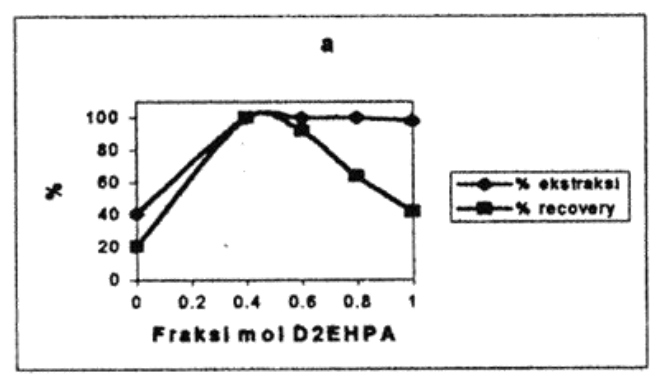

Gambar 8 (a) Kurva Hubungan \% ekstraksi dan \% recovery vs fraksi mol D2EHPA pada pH umpan 3 dan $\mathrm{pH}$ fasa stripping 1.

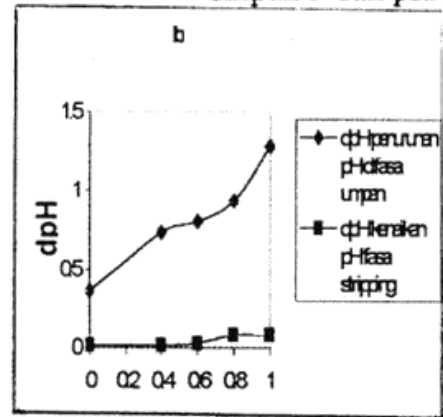

Gambar 8 (b) Kurva Hubungan dpH (perubahan pH) vs fraksi mol D2EHPA pada pH umpan 3 dan $\mathrm{pH}$ fasa stripping 1 . 


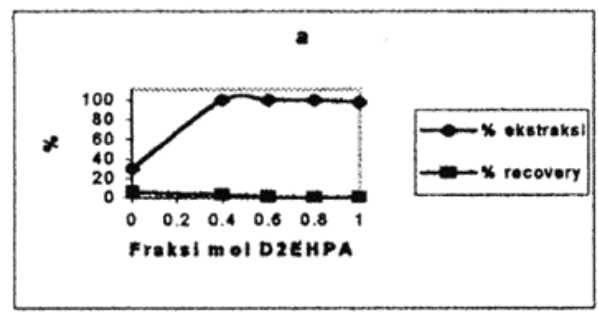

Gambar 9 (a) Kurva Hubungan \% ekstraksi dan \% recovery vs fraksi mol D2EHPA pada pH umpan 3 dan $\mathrm{pH}$ fasa air penerima 3.

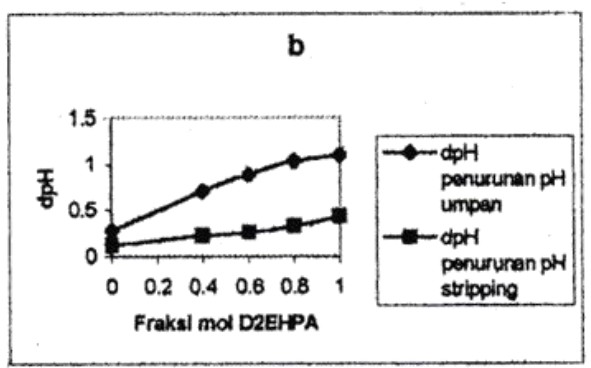

Gambar 9 (b) Kurva Hubungan dpH (perubahan pH) vs fraksi mol D2EHPA pada pH umpan 3 dan $\mathrm{pH}$ fasa air penerima 3 . 